\title{
Monoclonal Anti-TNF- $\alpha$ Antibodies for Severe Steroid-Dependent Asthma: A Case Series
}

\author{
Camille Taillé ${ }^{* 1,2,3}$, Claire Poulet ${ }^{1,4}$, Sylvain Marchand-Adam ${ }^{5,6}$, Raphaël Borie ${ }^{1}$, \\ Marie-Christine Dombret ${ }^{1}$, Bruno Crestani ${ }^{1,2,3}$ and Michel Aubier ${ }^{1,2,3}$
}

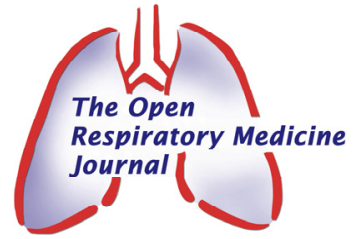

\author{
${ }^{1}$ Service de Pneumologie, Hôpital Bichat, Assistance Publique - Hôpitaux de Paris, Paris, France \\ ${ }^{2}$ Université Paris Diderot - Paris 7, Paris, France \\ ${ }^{3}$ INSERM Unité 700, Faculté de Médecine Bichat, Paris, France \\ ${ }^{4}$ Service de Pneumologie, Hôpital sud, Amiens, France \\ ${ }^{5}$ Service de Pneumologie, Hôpital Bretonneau, Tours, France \\ ${ }^{6}$ INSERM Unité 618, Faculté de Médecine, Tours, France
}

\begin{abstract}
Background: Refractory asthma represents an important condition, with considerable morbidity and mortality. Tumor necrosis factor $\alpha(\mathrm{TNF}-\alpha)$ is a potential target for treatment of severe asthma. However, controlled studies have shown controversial results and the risk-benefit profile of TNF-blocking agents is still debated.

Objectives: To describe the effect of infliximab on asthma control in patients with severe, uncontrolled, steroid-dependent asthma.

Methods: From 2007 to 2010, 7 patients received infliximab in our center. All had severe refractory asthma, with frequent severe exacerbations and hospitalizations in the intensive care unit despite maximal inhaled treatment, daily oral steroids and omalizumab treatment.

Results: Asthma control improved in the 6 patients who received infliximab for at least 3 months. Oral steroids could be stopped in 4 and the frequency of exacerbations and hospitalizations was greatly reduced, especially for the 3 patients with brittle asthma. Two patients showed severe adverse effects (bacterial pneumonia and extension of spreading melanoma). Three patients have received infliximab for more than 2 years, with good tolerance.

Conclusion: This case series suggests that anti-TNF- $\alpha$ drugs may improve the condition of a subgroup of patients with severe steroid-refractory asthma, with a favourable risk-benefit profile for most, considering asthma severity, occurrence of life-threatening exacerbations and complications of long-term oral steroids. Specific controlled trials of this subgroup are warranted.
\end{abstract}

Keywords: TNF- $\alpha$, severe refractory asthma, anti-TNF- $\alpha$ drug, brittle asthma.

\section{INTRODUCTION}

For some patients, asthma continues to be poorly controlled despite intensive treatment, and disease seems relatively unresponsive to corticosteroids. This severe refractory form of the disease represents considerable morbidity and mortality. Treatment options are limited and additional therapy is greatly needed.

Tumor necrosis factor $\alpha$ (TNF- $\alpha$ ) is a potential target for asthma treatment [1,2], especially severe asthma [3,4]. However, controlled studies have shown controversial results and the risk-benefit profile of TNF-blocking agents is still debated [5]. Recent studies suggest that a subset of

*Address correspondence to this author at the Service de Pneumologie A, Hôpital Bichat-Claude Bernard, 46 rue Henri Huchard, 75877 Paris cedex 18, France; Tel: 01402568 00; Fax: 01402588 18;

E-mail: camille.taille@bch.aphp.fr patients [6], who still need to be clearly identified, may benefit from anti-TNF- $\alpha$ drugs. We report our experience with infliximab in 7 patients with severe steroid-resistant asthma.

\section{METHODS}

\section{Subjects}

From February 2007 to April 2010, 195 patients were evaluated for severe asthma in our center. Among them, 7 adult patients were considered for anti-TNF- $\alpha$ treatment because of uncontrolled asthma with severe exacerbations and frequent hospitalizations. All had severe steroidrefractory disease according to the American Thoracic Society criteria [7]. Asthma control was unacceptable despite the best standard care treatment and careful repeated evaluation (including search for alternative diagnosis, comorbidities, environmental exposure, treatment adherence) 
by pulmonary physicians trained in asthma care. All were non- or ex-smokers.

All patients had received the maximal available inhaled asthma treatments and continuous oral steroids, and showed no improvement with omalizumab treatment for 6 months. Two patients did not fulfill the criteria for omalizumab because of total IgE level $<30 \mathrm{UI} / \mathrm{ml}$ (patient 1 ) or $>700$ $\mathrm{UI} / \mathrm{ml}$ (patient 3 ) but received the 6 months of omalizumab because of the severity of disease.

\section{Anti-TNF-a Treatment}

After medical evaluation according to the French Society for Rheumatology guidelines (http://www.rhumatologie.as so.fr/), patients received infliximab (Remicade, Centocor), 3 $\mathrm{mg} / \mathrm{kg}$ intravenously, at weeks $0,2,6$, and 12 . Patients with improved asthma control after 3 months (i.e., 4 injections), then received treatment every 6 weeks. When immediate hypersensitivity reaction occurred, treatment was switched to subcutaneous adalimumab (Humira, Abbot), $40 \mathrm{mg}$ every 2 weeks. All patients received oral information concerning potential risks and benefits of the treatment and gave their informed consent to treatment. Because the prescription for anti-TNF- $\alpha$ agents for asthma is off-label in France, this study was approved by the local institutional review board.

\section{Assessments}

Patients were prospectively evaluated at each visit (weeks 0, 2, 6, and 12), with particular emphasis on treatment tolerance and efficacy. Treatment outcomes were asthma control, as evaluated by the Asthma Control Test (ACT); the number of conventional and intensive-care-unit (ICU) hospitalizations related to asthma exacerbation; the number of exacerbations (defined as an increase in symptoms for more than $48 \mathrm{~h}$ requiring a change in asthma treatment) within the previous year and 1 year after antiTNF- $\alpha$ treatment; and weaning from oral steroid treatment. Spirometry was performed at inclusion and at 3 and 6 months of treatment. Side effects were considered severe if they required stopping anti-TNF-a therapy.

\section{Statistical Analysis}

Asthma control test scores from baseline to the last month of treatment were compared by a one way analysis of variance using GraphPadPrism 4.00 (GraphPad Software, California, USA).

\section{RESULTS}

\section{Characteristics of Patients}

Seven adult patients ( 5 females; mean age $50.8 \pm 9$ years) with severe uncontrolled asthma received infliximab. Their main characteristics are in Table 1. During the year preceding infliximab treatment, all patients presented more than 3 exacerbations. Four patients (patients 1,3,4,6) were considered to have brittle asthma and were frequently hospitalized in the ICU for severe exacerbations; 3 required mechanical ventilation. Two patients were ex-smokers and 2 had Vidal triad. One patient was considered to have occupational asthma secondary to isocyanate exposure.

\section{Treatment}

All patients received infliximab, and for 2, treatment was switched to adalimumab because of hypersensitivity reactions. The mean duration of anti-TNF- $\alpha$ treatment (infliximab and/or adalimumab) was $17.7 \pm 14$ months. Treatment efficacy could not be evaluated in patient 2 because she stopped the treatment just after the third infusion of infliximab, considering that her asthma remained too poorly controlled. Patient 5, despite improvement in ACT score and decrease in prednisone use from 20 to $5 \mathrm{mg} / \mathrm{d}$, stopped infliximab treatment after 4 months of treatment "for personal convenience," considering hospital visits too constraining. Three patients have received infliximab for more than 2 years, with excellent tolerance. In one patient, the treatment was stopped after 3 years of optimal asthma control with low-dose inhaled steroids. No exacerbation occurred during the first 18 months after withdrawal.

\section{Efficacy}

All 6 patients who could be evaluated after 3 months of anti-TNF- $\alpha$ treatment showed marked improvement in asthma control. Mean ACT increased from 8.1 \pm 1.6 to $15.6 \pm 4$ and $16.8 \pm 7.3$ after 3 and 6 months, respectively $(p=0.0019$, Fig. 1A). Oral steroids dose could be decreased in all patients except one. Four patients could be definitely weaned off continuous oral prednisone (Fig. 1B). The number of exacerbations was reduced. Three patients who were considered to have brittle asthma (1,3 and 4) showed the greatest improvement with anti-TNF- $\alpha$ therapy, with a decrease in number of hospitalizations and especially no need for ICU hospitalization during treatment. We observed no significant change in forced expiratory volume in $1 \mathrm{sec}$ $\left(\mathrm{FEV}_{1}\right)$ during treatment. In the 3 patients receiving infliximab for now 2 years, asthma control remains acceptable.

\section{Tolerance}

Two patients presented immediate hypersensitivity reactions (cutaneous rash, fever, tachycardia) after 1 and 2 infusions, so the treatment was changed to adalimumab, which was well tolerated. Three patients experienced fever as a minor adverse effect during infusion.

The 2 patients receiving adalimumab experienced severe adverse reactions that required treatment withdrawal, despite the beneficial effect on asthma control: 1 severe Pneumococcal pneumonia requiring mechanical ventilation and 1 spreading melanoma that extended during treatment.

\section{DISCUSSION}

We report here a case series supporting the use of infliximab for severe refractory asthma. In our patients, infliximab improved asthma control, had a marked oralsteroids sparing effect and strongly reduced asthma exacerbations and ICU hospitalizations.

Our cases were relatively homogenous and could be clinically characterized as severe steroid-dependent refractory asthma, with frequent exacerbations and daily symptoms despite close repeated medical evaluation and maximal treatment including oral steroids. Six-month 
Table 1. Characteristics of Patients with Severe Steroid-Refractory Asthma

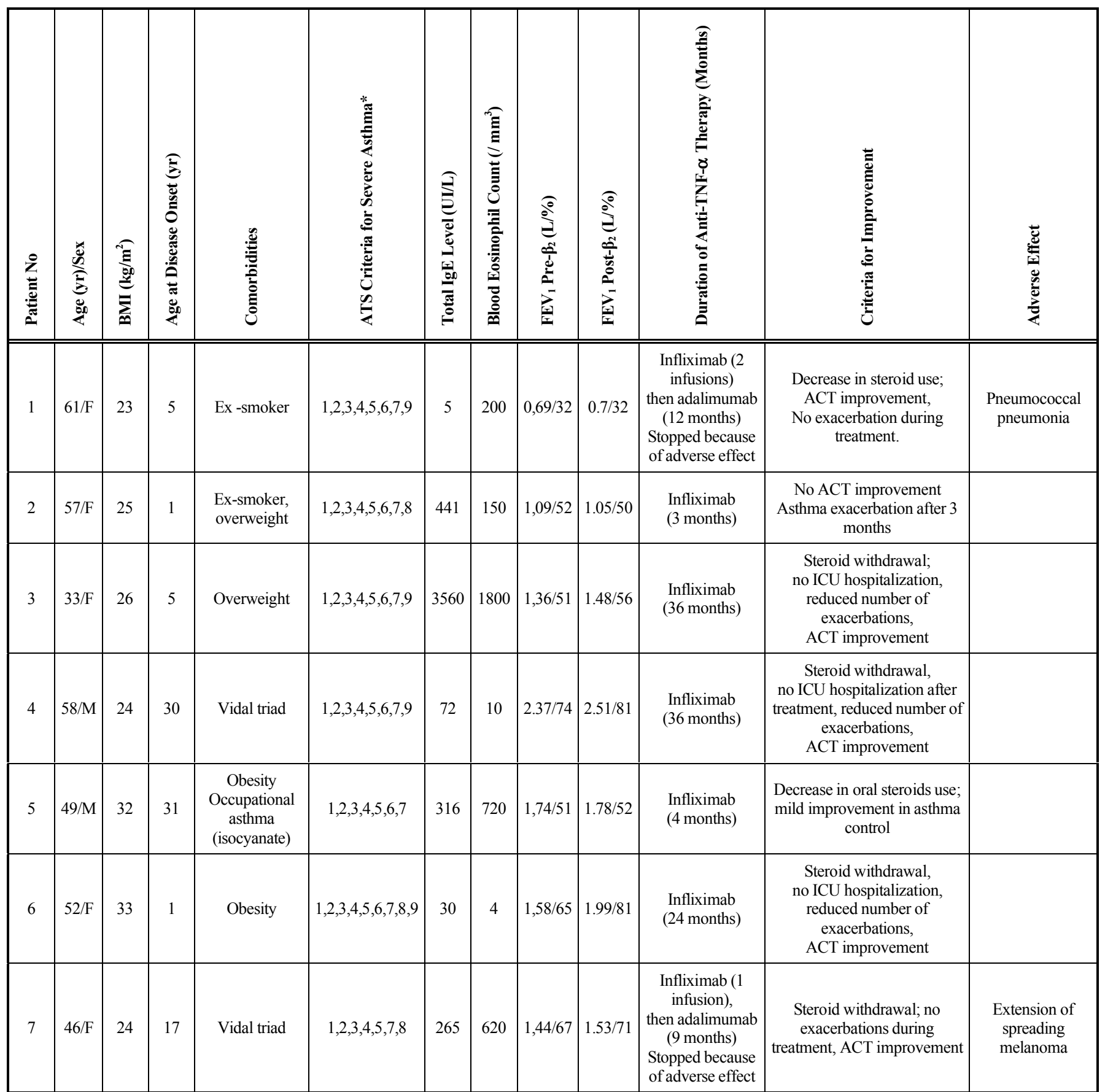

*The American Thoracic Society (ATS) criteria for refractory asthma are one or both of the following major criteria: 1) continuous treatment (for more than half of the year) with oral corticosteroids and 2) required treatment with high-dose inhaled corticosteroids; as well as 2 or more of the following minor criteria: 3 ) the need for daily "reliever" medication, 4) the presence of symptoms requiring daily treatment, 5) persistent airflow obstruction (defined by a forced expiratory volume in one second [FEV $\left.\mathrm{V}_{1}\right]<80 \%$ of the predicted value), 6) a history of one or more urgent care visits for asthma, 7) the need for 3 or more bursts of oral corticosteroids per year, 8) prompt deterioration in clinical condition after reduction of $<25 \%$ in corticosteroids dose, and 9) a history of near-fatal asthma.

ACT, Asthma Control Test.

treatment with non-effective omalizumab every 2 or 4 weeks in the hospital could limit the placebo effect of regular visits during infliximab administration.

Because of the frequent exacerbations and ICU admission within the previous year, the disease of all our patients would have been considered too severe for their inclusion in controlled trials evaluating TNF-blocking drugs.
The place of anti-TNF- $\alpha$ treatment in severe asthma is still debated despite a strong scientific rationale and several positive proof-of-concept studies [4,8-10]. One hypothesis explaining the controversial and disappointing results may be the different phenotypes of severe asthma among patient eligible for these trials. For example, recent results from the large controlled study of golimumab with negative results ${ }^{6}$ suggested improvement with TNF blockade for a subgroup of patients with severe asthma and rhinosinusitis and highly 


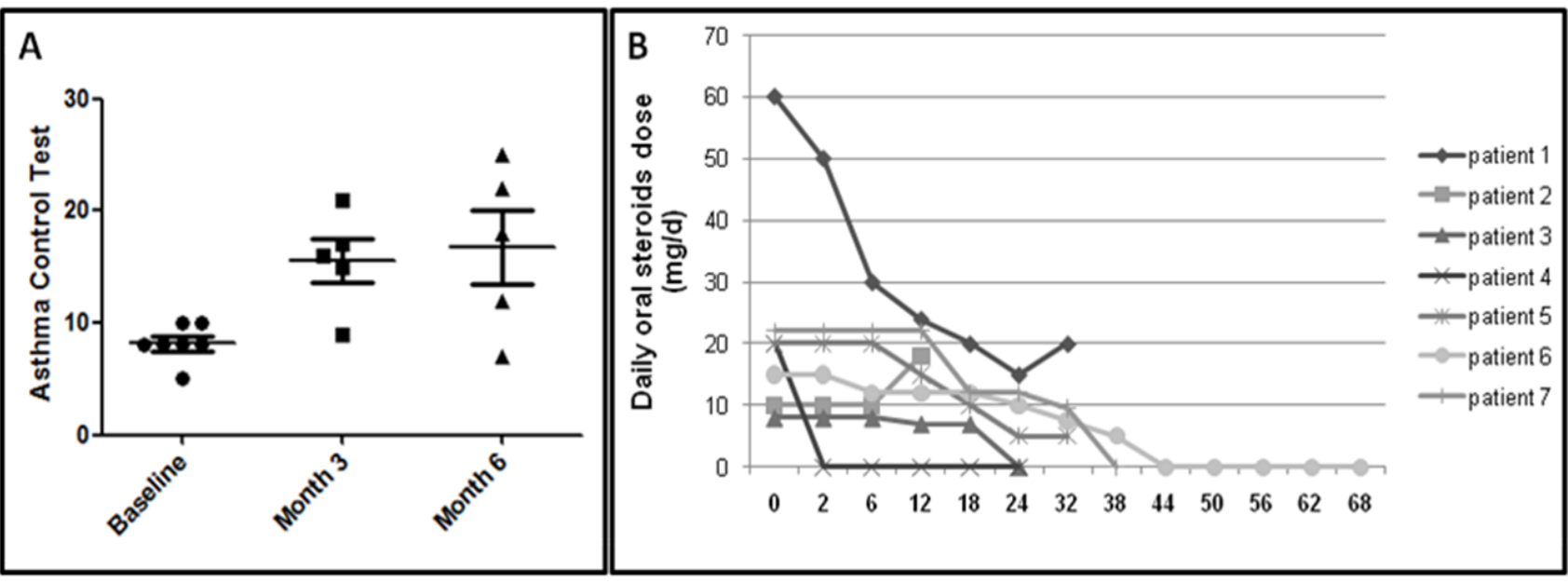

Fig. (1). (A) Efficacy of infliximab for asthma control after 3 and 6 months. Dots represent each patient. Bars and whiskers are mean \pm SD. (B) Need for daily oral steroids during follow-up (expressed as weeks after treatment).

reversible $\mathrm{FEV}_{1}$ [6,11]. The main characteristics of our patients were fixed airway obstruction (6/7) and overweight or obesity, which is associated with high TNF- $\alpha$ expression [12]. Such a clinical phenotype has been identified by cluster analysis from large cohorts of asthma patients [13]. In our series, patients with the greatest improvement were considered to have "brittle asthma", characterized by rapidonset and severe exacerbations. This subgroup of severe refractory asthma could represent another asthma phenotype [14], but whether it is associated with high TNF- $\alpha$ expression [15], which may predict sensitivity to TNF blockade, remains to be investigated.

We observed many serious adverse events, despite the small size of our sample. The 2 patients receiving adalimumab showed side effects. The most severe adverse effect was bacterial pneumonia. The role of long-term treatment with high doses of inhaled and/or oral steroids may explain the high rate of infections in patients with asthma receiving golimumab [6]. However, no unexpected safety findings were observed in 132 patients with moderate to severe asthma receiving etanercept for 12 weeks [16]. The pre-existence of melanoma in patient 7 would have represented a contra-indication for anti-TNF- $\alpha$ therapy, but we failed to detect it before treatment.

The relatively high rate of immediate hypersensitivity to treatment in our patients (2/7 patients) as compared with patients with rheumatoid arthritis may be explained by our patients not concurrently receiving methotrexate, which may promote immunologic tolerance of infliximab therapy. We found no evidence of bronchospasm during infliximab infusion, as is described in rheumatologic patients [17].

Three patients have received infliximab for more than 2 years, with excellent tolerance.

We believe that infliximab had a favourable risk-benefit profile in most of our patients, considering the asthma severity, occurrence of life-threatening exacerbations and complications of long-term oral steroids. This subgroup of severe refractory asthma with frequent exacerbation may represent a particular clinical phenotype with high efficacy of infliximab. Specific controlled trials should be designed for these patients with severe steroid-refractory asthma to assess this hypothesis. Characterization of the airway inflammatory profile and gene expression pattern in the sputum [15] would help identify biomarkers of patients most likely to respond to such treatment.

Infliximab may improve the condition of some patients with severe steroid-dependant refractory asthma, although this small series does not allow for definitive conclusions. Careful medical evaluation is warranted before and during treatment. A properly designed, randomized trial of a larger group of severe steroid-refractory patients is needed to confirm the benefit/risk ratio of anti-TNF- $\alpha$ treatment in this particular population.

\section{CONFLICT OF INTEREST}

The authors confirm that this article content has no conflict of interest.

\section{ACKNOWLEDGEMENTS}

Declared none.

\section{REFERENCES}

[1] Russo C, Polosa R. TNF-alpha as a promising therapeutic target in chronic asthma: a lesson from rheumatoid arthritis. Clin Sci 2005 109(2): 135-42.

[2] Brightling C, Berry M, Amrani Y. Targeting TNF-alpha: a novel therapeutic approach for asthma. J Allergy Clin Immunol 2008; 121(1): 5-10.

[3] Holgate ST, Polosa R. The mechanisms, diagnosis, and management of severe asthma in adults. Lancet 2006; 368(9537) 780-93.

[4] Howarth PH, Babu KS, Arshad HS, et al. Tumour necrosis factor (TNFalpha) as a novel therapeutic target in symptomatic corticosteroid dependent asthma. Thorax 2005; 60(12): 1012-8.

[5] Cox LS. How safe are the biologicals in treating asthma and rhinitis? Allergy Asthma Clin Immunol 2009; 5(1): 4.

[6] Wenzel SE, Barnes PJ, Bleecker ER, et al. A randomized, doubleblind, placebo-controlled study of tumor necrosis factor-alpha blockade in severe persistent asthma. Am J Respir Crit Care Med 2009; 179(7): 549-58.

[7] Proceedings of the ATS workshop on refractory asthma: current understanding, recommendations, and unanswered questions. Am J Respir Crit Care Med 2000;162(6): 2341-51.

[8] Morjaria JB, Chauhan AJ, Babu KS, Polosa R, Davies DE, Holgate $\mathrm{ST}$. The role of a soluble TNFalpha receptor fusion protein (etanercept) in corticosteroid refractory asthma: a double blind, randomised, placebo controlled trial. Thorax 2008; 63(7): 584-91. 
[9] Berry MA, Hargadon B, Shelley M, et al. Evidence of a role of tumor necrosis factor alpha in refractory asthma. N Engl $\mathrm{J}$ Med 2006; 354(7): 697-708.

[10] Holgate ST, Noonan M, Chanez P, et al. Efficacy and safety of etanercept in moderate-to-severe asthma: a randomised, controlled trial. Eur Respir J 2011; 37(6): 1352-9.

[11] Levine SJ, Wenzel SE. Narrative review: the role of Th2 immune pathway modulation in the treatment of severe asthma and its phenotypes. Ann Intern Med 2010; 152(4): 232-7.

[12] Sutherland ER, Goleva E, Strand M, Beuther DA, Leung DY. Body mass and glucocorticoid response in asthma. Am J Respir Crit Care Med 2008; 178(7): 682-7.
[13] Moore WC, Meyers DA, Wenzel SE, et al. Identification of asthma phenotypes using cluster analysis in the Severe Asthma Research Program. Am J Respir Crit Care Med 2010; 181(4): 315-23.

[14] Bush A, Fleming L. Phenotypes of refractory/severe asthma. Paediatr Respir Rev 2011; 12(3): 177-81.

[15] Baines KJ, Simpson JL, Wood LG, Scott RJ, Gibson PG. Transcriptional phenotypes of asthma defined by gene expression profiling of induced sputum samples. J Allergy Clin Immunol 2011; 127(1): 153-60

[16] Holgate ST, Noonan M, Chanez P, et al. Efficacy/safety of etanercept in moderate-to-severe asthma: a randomised, controlled trial. Eur Respir J 2011; 37(6): 1352-9.

[17] Dubey S, Kerrigan N, Mills K, Scott DG. Bronchospasm associated with anti-TNF treatment. Clin Rheumatol 2009; 28(8): 989-92.

(C) Taillé et al.; Licensee Bentham Open.

This is an open access article licensed under the terms of the Creative Commons Attribution Non-Commercial License (http://creativecommons.org/licenses/by-nc/3.0/) which permits unrestricted, non-commercial use, distribution and reproduction in any medium, provided the work is properly cited. 